REF - ISSN 1808-0804 Vol. IX (2), 37 - 48, 2012.

\title{
PERFIL FARMACOGNÓSTICO E AVALIAÇÃo DAS ATIVIDADES CITOTÓXICA E ANTIBACTERIANA DE Bromelia antiacantha BERTOL.
}

PHARMACOGNOSTIC PROFILE AND EVALUATION OF ANTIBACTERIAL AND CYTOTOXIC ACTIVITIES OF THE Bromelia antiacantha BERTOL.

\author{
Rodrigo Luiz Fabri ${ }^{1}$, Juliana Aparecida Batista Marques da Costa² \\ ${ }^{1}$ Professor Adjunto I; Faculdade de Ciências da Saúde; Universidade Presidente \\ Antônio Carlos/Juiz de Fora/ Minas Gerais \\ ${ }^{2}$ Aluna de Graduação do Curso de Buiomedicina; Faculdade de Ciências da Saúde; \\ Universidade Presidente Antônio Carlos/Juiz de Fora/ Minas Gerais \\ *autor para correspondência: rodrigolfabri@yahoo.com.br
}

Recebido em 06/05/2012, Aceito em 28/05/2012.

\begin{abstract}
RESUMO: O objetivo deste estudo foi investigar o potencial químico-terapêutico para as atividades citotóxica e antibacteriana de Bromelia antiacantha Bertol., coletada no sudeste do Brasil. Além disso, identificar as principais classes de constituintes fitoquímicos presentes na espécie. As folhas e frutos de $B$. antiacantha foram coletados e os respectivos extratos foram preparados. A atividade citotóxica foi avaliada frente à Artemia salina e a atividade antibacteriana foi realizada para seis linhagens de bactérias, Staphylococcus aureus, Pseudomonas aeruginosa, Escherichia coli, Shigella dysenteriae, Salmonella enterica sorovar tythimurium e Enterobacter cloacae. Os principais fitoconstituintes encontrados nas amostras foram alcaloides, fenóis, flavonoides, triterpenos e esteroides. O teste de citotoxicidade mostrou que os extratos e partições das folhas e frutos de $B$. antiacantha tiveram moderada toxicidade, sendo mais efetiva para partição em diclorometano dos frutos. Em relação à atividade antibacteriana, os
\end{abstract}


Fabri, R. L. da Costa, J. A. B. M. Revista Eletrônica de Farmácia Vol. IX (2), 37 - 48, 2012.

extratos e partições de $B$. antiacantha foram ativos somente contra as linhagens de $P$. aeruginosa e E. coli, principalmente o extrato metanólico das folhas. Bromelia antiacantha se apresenta como uma fonte promissora de substâncias bioativas principalmente em relação à $P$. aeruginosa e E. coli.

PALAVRAS-CHAVE: Bromelia; toxicidade de drogas; Pseudomonas aeruginosa; Escherichia coli.

ABSTRACT: The aim of this study was to investigate the chemical-therapeutic potential of Bromelia antiacantha Bertol., collected in southeastern Brazil, for the cytotoxic and antibacterial activities and identify the main phytochemical groups shown in the species. Leaves and fruits of $B$. antiacantha were collected and their respective extracts were prepared. The cytotoxic activity was evaluated against Artemia salina and antibacterial activity was performed for six bacteria strains, Staphylococcus aureus, Pseudomonas aeruginosa, Escherichia coli, Shigella dysenteriae, Salmonella enterica sorovar tythimurium and Enterobacter cloacae. The main phytoconstituents found in the samples were alkaloids, phenols, flavonoids, triterpenes and steroids. The cytotoxicity assay showed that the extracts and partitions of leaves and fruits of $B$. antiacantha had moderate toxicity, being most effective in dichloromethane partition of the fruits.In regard to the antibacterial activity, $B$. antiacantha extracts and partitions were active only against $P$. aeruginosa and $E$. coli strains, mainly the methanolic extract of the leaves. Bromelia antiacantha shows itself as a promising source of bioactive substances mainly against $P$. aeruginosa and $E$. coli.

KEYWORDS: Bromelia; toxicity of drugs; Pseudomonas aeruginosa; Escherichia coli

\section{INTRODUÇÃO}

O uso de plantas medicinais para o tratamento de muitas doenças está associado à medicina popular de

que acompanham o homem desde a pré- história e que evoluíram com ele ao longo dos anos ${ }^{(2)}$.

O uso de plantas medicinais pela população mundial tem sido muito significativo nos últimos tempos. Segundo De acordo com a Organização Mundial de Saúde (OMS), 80\% das diferentes partes do mundo(1). Diversas culturas dos mais distintos lugares, desenvolvidas ou não têm utilizado o potencial terapêutico dos vegetais no tratamento de doenças, práticas estas pessoas dos países em desenvolvimento no mundo, dependem da medicina tradicional para as suas necessidades básicas de saúde e cerca de $85 \%$ da medicina tradicional envolve o uso de plantas ou extratos desta ${ }^{(3)}$.

De acordo com o DECRETO $n^{\circ}$ 5813 de 22 de junho de 2006, ficou 
Fabri, R. L. da Costa, J. A. B. M. Revista Eletrônica de Farmácia Vol. IX (2), 37 - 48, 2012.

aprovada a Política Nacional de Plantas Medicinais, garantindo à população fitoterápicos, ampliando as opções terapêuticas aos usuários, com segurança, eficácia e qualidade, na perspectiva da integridade da atenção à saúde, considerando o conhecimento tradicional sobre plantas medicinais ${ }^{(4)}$.

A Bromelia antiacantha Bertol. é uma planta popularmente conhecida como "aguama", "piña de ratón", e "gravatá" nos países do México, Peru e Brasil. No Brasil essa espécie pode ser encontrada nas regiões sul e sudeste, sendo caracterizada popularmente pelos nomes de gravatá, caraguatá, croata e caruatá $^{(5,6)}$. Segundo Reitz ${ }^{(7)}$, os índios bororós no sul do Brasil ferviam os frutos para tratar a tosse e usavam como emoliente, uma tradição que foi continuada pelos colonizadores europeus.

Segundo Píon-Leon et al. ${ }^{(8)}$ na América Central, a planta é utilizada para fins terapêuticos e alimentares, sendo o fruto cozido a principal parte utilizada para o tratamento de tosse, bronquite, diabetes e escorbuto. Além disso, os autores observaram que o fruto apresentou atividade antibacteriana, principalmente para bactérias Gram positivas e correlacionaram essa atividade com os compostos fenólicos presentes no fruto, entre eles taninos e flavonóides. Em outro estudo realizado no sul do Brasil, com a mesma espécie, também foi observado atividade dos frutos e folhas para bactérias Gram brasileira o acesso seguro e o uso racional de plantas medicinais $e$ positivas, destacando Staphylococcus aureus $^{(9)}$.

Por considerar relevante 0 potencial antibacteriano de espécies vegetais frente às bactérias causadoras de infecções relacionadas ao cuidado em saúde, propõe-se nesse estudo explorar o potencial químico-terapêutico para as atividades antibacteriana e citotóxica e identificar as principais classes de constituintes fitoquímicos de Bromelia antiacantha, coletada do sudeste do Brasil.

\section{MATERIAIS E MÉTODOS}

\section{Material vegetal}

As folhas e frutos de Bromelia antiacantha Bertol foram coletadas na zona rural da cidade de Rio Pomba MG, Brasil, em agosto de 2010. A exsicata foi depositada no Herbário Leopoldo Krieger (CESJ 4226) da Universidade Federal de Juiz de Fora/MG.

\section{Preparação do extrato metanólico e das partições}

As folhas e frutos de $B$. antiacantha foram secas em estufa com circulação de ar a $40^{\circ} \mathrm{C}$ e pulverizadas, a fim de obter o material vegetal seco da folha e do fruto $(39,6 \quad \mathrm{~g}$ e $129,5 \mathrm{~g}$ respectivamente). Estes materiais foram extraídos por maceração com metanol 
Fabri, R. L. da Costa, J. A. B. M. Revista Eletrônica de Farmácia Vol. IX (2), 37 - 48, 2012.

$(\mathrm{MeOH})$, à temperatura ambiente, até a exaustão. Os extratos foram concentrados à pressão reduzida utilizando evaporador rotatório,obtendo $18,2 \mathrm{~g}$ de extrato das folhas e $36,9 \mathrm{~g}$ de extrato dos frutos.

Os extratos metanólicos (10 g), após a remoção do solvente, foram ressuspendidos em $\mathrm{MeOH}$ : água (8:2) e, em seguida, particionado com solventes de polaridade crescente: hexano, diclorometano e acetato de etila ( $3 \times 200$ $\mathrm{ml}$ ). Os solventes foram evaporados e as partições foram pesadas e mantidas sobre refrigeração até o momento da realização dos ensaios fitoquímicos e biológicos.

\section{Análise fitoquímica}

As amostras (extratos e partições) foram submetidas às análises para determinação das principais classes químicas e metabólitos especiais, de acordo com o protocolo descrito por Matos $^{(10)}$, com algumas modificações. Resumidamente, as amostras foram suspendidas em $\mathrm{MeOH}(1 \mathrm{mg} / \mathrm{ml})$ e os seguintes testes foram realizados: taninos por meio da reação com gelatina 2,5\%; triterpenos e esteroides pelo reativo de Liebermann-Burchard; alcaloides pelos reativos de Dragendorff, Bouchardat, Mayer e Bertrand; fenóis pela reação com $\mathrm{FeCl}_{3} 5 \%$; flavonoides pela reação de Shinoda e $\mathrm{AlCl}_{3} 5 \%$; antraquinonas pela reação de Borntraeger; saponinas pelo teste de formação de espuma persistente e cumarinas pela reação com KOH $10 \%$.

\section{Atividade citotóxica}

A presença de constituintes citotóxicos foi avaliada utilizando-se a metodologia proposta por Meyer et al. (11). Larvas de Artemia salina (microcrustáceos), obtidas a partir de ovos utilizados como ração para peixes ornamentais (TROPFISH $®$ ), foram colocadas para eclodir em aquário com água do mar artificial arejada durante 48 horas. Esse microcrustáceo é amplamente testado em ensaios de toxicidade devido à rapidez de seu crescimento e o baixo custo de criação e manutenção em laboratório. As amostras solubilizadas em água do mar artificial, com a ajuda de um diluente (DMSO 1\%). Os testes foram realizados em tubos de ensaio com 10 náuplios, preenchidos com 4,5 ml de água do mar artificial e $0,5 \mathrm{ml}$ das amostras. As amostras foram testadas em 5 concentrações diferentes de 1000 à $10 \mu \mathrm{g} / \mathrm{ml}$. Após 24 horas foram contados os crustáceos vivos nas diferentes concentrações. Timol e a água do mar artificial + DMSO $1 \%$ foram usados como controles positivo e negativo, respectivamente. Os testes foram realizados em triplicata. Os resultados foram expressos em $\mathrm{CL}_{50}$ (concentração necessária para matar $50 \%$ dos microcrustáceos) que foi calculado pelo programa estatístico Probit. 
Fabri, R. L. da Costa, J. A. B. M. Revista Eletrônica de Farmácia Vol. IX (2), 37 - 48, 2012.

\section{Atividade antibacteriana}

\section{Método de difusão em Agar}

As linhagens padrão de bactérias usadas neste trabalho foram Staphylococcus aureus (ATCC 6538), Pseudomonas aeruginosa (ATCC 15442), Escherichia coli (ATCC 10536), Shigella dysenteriae (ATCC 13313), Salmonella enterica sorovar typhimurium (ATCC 13311) e Enterobacter cloacae (ATCC 10699). A avaliação da atividade antibacteriana foi realizada de acordo com os protocolos descritos na literatura $^{(12,13)}$. O meio de cultura foi 0 ágar Mueller-Hinton, preparado de acordo com as instruções do fabricante e colocados em placas de Petri. Inicialmente foi feito um inóculo com as colônias das linhagens padrão com uma alça de platina fazendo o repique em placa de Petri deixando em estufa biológica por 24 horas para crescimento. O inóculo foi adicionado à salina estéril para a padronização de uma densidade microbiana de 0,5 a 1,0 da escala de McFarland $\left(10^{8}\right.$ células $\left./ \mathrm{ml}\right)$. Em seguida $100 \mu \mathrm{l}$ do inóculo foi aplicado em ágar
Mueller-Hinton com o auxílio de um bastão em $L$ de vidro. Após 15 minutos, foram feitos poços de $6 \mathrm{~mm}$ de diâmentro no ágar com o auxílio de um perfurador apropriado. As amostras vegetais foram diluídas em DMSO para uma concentração final de $5 \mathrm{mg} / \mathrm{ml}$ e uma alíquota de $50 \mu \mathrm{l}$ de cada extrato foi colocado, assepticamente, nos poços da placa de cultura, previamente semeada com a bactéria. As placas foram incubadas a $37^{\circ} \mathrm{C}$, e observadas após 24 horas. O diâmetro da zona de inibição foi expresso em $\mathrm{mm}$. Todos os testes foram realizados em duplicata. Para controle positivo foi utilizado os antibióticos amoxilina $(30 \mu \mathrm{g})$, eritromicina $(2 \mu \mathrm{g})$ e cloranfenicol $(30 \mu \mathrm{g})$ e para controle negativo, DMSO.

\section{RESULTADOS}

\section{Análise Fitoquímica}

Os resultados da triagem fitoquímica dos extratos metanólicos e partições das folhas e frutos de $B$. antiacantha estão representados na Tabela 1.

Tabela 1: Triagem fitoquímica do extrato metanólico e partições das folhas e frutos de Bromelia antiacantha.

\begin{tabular}{lcccccccccc}
\hline \multirow{2}{*}{ Amostras $^{\mathrm{a}}$} & \multicolumn{10}{c}{ Principais fitoconstituintes } \\
& Al & Sa & Fe & Fl & Ta & Tr & Es & An & Cm \\
\hline Folha & & & & & & & & & & \\
BAM & + & - & + & + & + & + & + & - & + \\
BAH & + & - & - & - & + & - & + & - & -
\end{tabular}


Fabri, R. L. da Costa, J. A. B. M. Revista Eletrônica de Farmácia Vol. IX (2), 37 - 48, 2012.

BAD

BAA

BAHa

Fruto

BAM

BAH

BAD

BAA

$\mathrm{BAHa}$

$\begin{array}{lllllllll}+ & - & + & + & + & + & + & + & + \\ + & - & + & + & + & + & - & - & - \\ + & - & + & + & - & - & - & - & - \\ + & - & + & + & - & - & + & - & - \\ - & - & + & + & - & + & - & + & -\end{array}$

a BAM - extrato metanólico; BAH - partição em hexano; BAD - partição em diclorometano; BAA - partição em acetato de etila e BAHa - partição hidrometanólica.

b Al - alcaloides; Sa - saponinas; Fe - fenóis; - FI - flavonoides; Ta - taninos; Tr - triterpenos; Es esteroides; An - antraquinonas e $\mathrm{Cm}$ - cumarinas.

\section{Atividade citotóxica}

Os resultados do teste de letalidade

contra Artemia salina estão expressos na
Tabela 2. $\mathrm{CL}_{50}<250,0 \mu \mathrm{g} / \mathrm{ml}$ foi considerado significante para extratos vegetais $^{(14)}$.

Tabela 2: Teste de citotoxicidade do extrato metanólico e partições das folhas e frutos de Bromelia antiacantha.

\begin{tabular}{ll}
\hline Amostras $^{\mathrm{a}}$ & $\begin{array}{l}\text { Atividade citotóxica } \\
\mathrm{CL}_{50}(\mu \mathrm{g} / \mathrm{ml})^{\mathrm{b}}\end{array}$ \\
\hline Folha & $>1000$ \\
BAM & $241,6(124,4-469,1)$ \\
BAH & $112,4(49,0-250,0)$ \\
BAD & $53,9(21,0-138,2)$ \\
BAA & $>1000$ \\
BAHa & $>1000$ \\
Fruto & $>1000$ \\
BAM & $29,8(14,2-62,4)$ \\
BAH & $>1000$ \\
BAD & $>1000$ \\
BAA & $1,4(0,7-3,0)$ \\
BAHa & \\
Timol & \\
\hline
\end{tabular}


Fabri, R. L. da Costa, J. A. B. M. Revista Eletrônica de Farmácia Vol. IX (2), 37 - 48, 2012.

a BAM - extrato metanólico; BAH - partição em hexano; BAD - partição em diclorometano; BAA partição em acetato de etila e BAHa - partição hidrometanólica.

${ }^{\mathrm{b}} 95 \%$ intervalo de confiança em parênteses

${ }^{\mathrm{c}}$ Controle positivo

\section{Atividade antimicrobiana}

O método de diluição em ágar foi realizado com o objetivo de se avaliar qualitativamente a atividade antibacteriana das amostras. Os resultados estão apresentados na Tabela 3.

Tabela 3: Atividade antibacteriana do extrato metanólico e partições das folhas e frutos de Bromelia antiacantha.

\begin{tabular}{|c|c|c|c|c|c|c|}
\hline \multirow{3}{*}{ Amostras $^{a}$} & \multicolumn{4}{|c|}{ Atividade antibacteriana $^{b}$} & \multirow[b]{3}{*}{ En } & \multirow[b]{3}{*}{ St } \\
\hline & & (Halc & $\mathrm{mn}$ & & & \\
\hline & $\mathrm{Sa}$ & $\mathrm{Sd}$ & $\mathrm{Pa}$ & Ec & & \\
\hline \multicolumn{7}{|l|}{ Folha } \\
\hline BAM & 0 & 0 & 11 & 8 & 0 & 0 \\
\hline BAH & 0 & 0 & 0 & 0 & 0 & 0 \\
\hline BAD & 0 & 0 & 11 & 0 & 0 & 0 \\
\hline BAA & 0 & 0 & 0 & 0 & 0 & 0 \\
\hline $\mathrm{BAHa}$ & 0 & 0 & 0 & 0 & 0 & 0 \\
\hline \multicolumn{7}{|l|}{ Fruto } \\
\hline BAM & 0 & 0 & 0 & 0 & 0 & 0 \\
\hline $\mathrm{BAH}$ & 0 & 0 & 0 & 0 & 0 & 0 \\
\hline BAD & 0 & 0 & 0 & 0 & 0 & 0 \\
\hline BAA & 0 & 0 & 10 & 0 & 0 & 0 \\
\hline $\mathrm{BAHa}$ & 0 & 0 & 0 & 0 & 0 & 0 \\
\hline Amoxilina $^{c}$ & 20 & 0 & 0 & 24,5 & 0 & 0 \\
\hline Eritromicina $^{c}$ & 15 & 0 & 0 & 14,5 & 0 & 0 \\
\hline Cloranfenicol $^{\mathrm{C}}$ & 20 & 32 & 28 & 18 & 30 & 30 \\
\hline $\mathrm{DMSO}^{\mathrm{d}}$ & 0 & 0 & 0 & 0 & 0 & 0 \\
\hline
\end{tabular}

${ }^{a}$ BAM - extrato metanólico; BAH - partição em hexano; BAD - partição em diclorometano; BAA partição em acetato de etila e BAHa - partição hidrometanólica.

b Sd - Shigella dysenteriae; Sa - Staphylococcus aureus; Pa - Pseudomonas aeruginosa; Ec Escherichia coli; En - Enterobacter cloacae e St - Salmonella entérica sorovar tythimurium

${ }^{c}$ Controles positivos

${ }^{\mathrm{d}}$ Controle negativo 
Fabri, R. L. da Costa, J. A. B. M. Revista Eletrônica de Farmácia Vol. IX (2), 37 - 48, 2012.

\section{DISCUSSÃo}

Os resultados obtidos na análise fitoquímica para o extrato metanólico e partições das folhas e frutos de $B$. antiacantha foram semelhantes, sendo que os alcaloides foram identificados em todas as amostras, exceto BAHa (Tabela 1). Fenóis e flavonoides só não foram observados em BAH das folhas. Antraquinonas foi identificado somente em BAM e BAHa dos frutos. Triterpenos foram positivos para BAM e BAHa das folhas e BAM, BAH e BAHa dos frutos e esteroides não foram identificados no BAHa das folhas e nos frutos esteve presente em BAM e BAA. Já taninos e cumarinas foram identificados em BAM e BAH, e BAM, respectivamente, tanto de folhas quanto de frutos. Saponinas não foram observadas em nenhuma das amostras testadas.

O bioensaio de toxidez frente à Artemia salina tem sido utilizado para seleção de extratos de plantas com substâncias de potencial farmacológico. 0 teste de citotoxicidade contra o microcrustáceo tem uma correlação positiva com atividade para células tumorais principalmente para células leucêmicas KB, sendo uma ferramenta útil para a determinação preliminar da atividade antitumoral ${ }^{(15)}$. Além da atividade antitumoral, outros testes farmacológicos também possuem ligação com essa atividade, destacando pesticida(15), tripanomicida $^{(16)}$ e antimaláricos $^{(17)}$. No presente estudo foi observado que para as folhas $B$. antiacantha, somente as $\mathrm{BAH}, \mathrm{BAD}$ e BAA apresentaram citotoxicidade com $\mathrm{CL}_{50}$ de 53,9; 112,4 e 241,6 $\mathrm{\mu g} / \mathrm{ml}$, respectivamente (Tabela 2). Já em relação aos frutos, BAD foi à única que obteve atividade com $\mathrm{CL}_{50} 29,8 \mu \mathrm{g} / \mathrm{ml}$. De acordo com Rieser et al. ${ }^{(14)}$, somente BAD de ambas partes usadas e BAA da folha apresentaram citotoxicidade significativa, sendo o $\mathrm{CL}_{50}<250,0 \mu \mathrm{g} / \mathrm{ml}$. Este estudo corrobora com o trabalho realizado, no sul do Brasil, por Manetti et al. ${ }^{(9)}$, o qual identificou toxicidade no extrato alcoólico das folhas e frutos de $B$. antiacantha.

Os ensaios com bactérias tem sido de suma importância devido à frequência de resistência microbiana que tem levado ao aumento de infecções graves. A resistência por muitos microorganismos tem causado graves problemas de saúde pública e prejuízos econômicos $^{(18,19)}$. A A Atividade antibacteriana foi observada tanto para as folhas quanto para os frutos de $B$. antiacantha, sendo susceptíveis somente duas linhagens de bactérias, Pseudomonas aeruginosa e Escherichia coli. Em relação a $P$. aeruginosa as amostras ativas foram BAM e BAD das folhas e BAA dos frutos. Já para $E$. coli somente BAM das folhas apresentou atividade.

Esses resultados são extremamente importantes visto que 
Fabri, R. L. da Costa, J. A. B. M. Revista Eletrônica de Farmácia Vol. IX (2), 37 - 48, 2012.

bactérias Gram-negativas como $E$. coli e $P$. aeruginosa são responsáveis por elevada incidência de infecções. As infecções mais freqüentes em UTIs são aquelas causadas por bacilos Gramnegativos, como $P$. aeruginosa, em especial pneumonias associadas à ventilação mecânica. No Brasil, a resistência a $P$. aeruginosa é muito preocupante. Nas UTIs dos grandes hospitais, resistência a $P$. aeruginosa é de 20 a $75 \%$ para antibióticos betalactâmicos e aminoglicosídeos e isso vem acompanhado de resistência cruzada(20).

Mecanismos de ação antibacteriana para algumas dessas classes já foram descritos. Para os alcaloides, essa propriedade pode ser atribuída a sua habilidade de intercalarem com o DNA microbiano $^{(21)}$. Para triterpenos e esteroides, o mecanismo de ação ainda não está bem esclarecido, mas especulase que estejam envolvidos na ruptura de compostos lipofílicos das membranas microbianas $^{(22,23)}$. Os compostos fenólicos possuem uma relativa toxidez a microrganismos devido à localização e ao número de grupos hidroxilas presentes nos grupamentos fenólicos, sendo que quanto maior o número de hidroxilações, maior a toxicidade ${ }^{(24)}$. Além disso, já foi descrito que quanto maior a oxidação dos fenóis, maior seu efeito inibitório(25). o mecanismo responsável pela toxicidade de compostos fenólicos para microrganismos inclui a inibição enzimática por compostos oxidados, possivelmente através de reações com grupos sulfidrilas ou por interações não específicas com as proteínas ${ }^{(26)}$. Os flavonoides, de maneira geral, são conhecidos por serem sintetizados por plantas em resposta a infecção microbiana ${ }^{(27)}$. Sua atividade é provavelmente devido à habilidade de se complexarem com as proteínas extracelulares e solúveis e com a parede celular bacteriana. Flavonoides lipofílicos podem romper a membrana microbiana $^{(27)}$. Já os taninos apresentam seu mecanismo de ação provavelmente por inativar proteínas como as adesinas bacterianas, enzimas e proteínas transportadoras da parede celular ${ }^{(28)}$.

\section{CONCLUSÃO}

Bromelia antiacantha se apresenta como uma fonte promissora de substâncias bioativas principalmente em relação à Pseudomonas aeruginosa e Escherichia coli. Estudo fitoquímico preliminar mostrou que essa espécie possui principalmente alcaloides, triterpenos, esteroides e flavonoides. Os resultados obtidos reforçam a necessidades de novas pesquisas a fim de ampliar os conhecimentos sobre as propriedades biológicas da espécie.

\section{AGRADECIMENTOS}

Os autores agradecem a Doutora Fátima Regina Salimena pela identificação botânica da espécie vegetal. 
Fabri, R. L. da Costa, J. A. B. M. Revista Eletrônica de Farmácia Vol. IX (2), 37 - 48, 2012.

\section{REFERÊNCIAS}

1. Araújo CAC, Leon LL. Biological activities of Curcuma longa L. Mem. Inst Oswaldo Cruz. 2001;96(5):723-728.

2. Coutinho MR, Quadri MB, Moreira RFPM, Quadri MGN. Partial purification of anthocyanins from Brassica oleracea (red cabbage). Sep. Sci. Technol. $2004 ; 39(16): 3769-3782$.

3. Calixto JB. Efficacy, safety, quality control, marketing and regulatory guidelines for herbal medicines (phytotherapeutic agents). Braz. J. Med. Biol. Res. 2000;33(2):179189.

4. Brasil, Ministério da Saúde. Atos do Poder Executivo. Decreto n. 5813, de 22 de junho de 2006. Aprova a Política Nacional de Plantas Medicinais e Fitoterápicos e dá outras providências. Diário Oficial da União, Brasília (Brasil): Ministério da Saúde, 2006.

5. Lorenzi HE, Matos FJA. Plantas medicinais no Brasil - nativas e exóticas. Nova Odessa: Instituto Plantarum; 2002. 512 p.

6. Vallés D, Furtado S, Cantera AMB. Characterization of news proteolytic enzymes from ripe fruits of Bromelia antiacantha Bertol (Bromeliaceae). Int. Conf. Enzyme Technol. 2007;40(3):409-413.

7. Reitz R. Bromeliáceas e a malária - bromélia endêmica. In: Reitz R. (Ed). Flora Ilustrada Catarinense. Itajaí: Herbário Barbosa Rodrigues; 1983.

8. Píon-Leon JF, López-Angulo G, Paredes-Lopes O, Uribe-Beltrán MJ, Diaz-Camacho SP, Delgado-Vargas F. Physicochemical nutritional and antibacterial characteristics of the fruit of Bromelia penguin L. Plant Foods Hum. Nutr. 2009;64(3):181-187.

9. Manetti LM, Turra AF, Takemura OS, Svidzinski TIE, Júnior AL. Avaliação das atividades antimicrobiana, citotóxica, moluscicida e antioxidante de Bromelia antiacantha Bertol. (Bromeliaceae). Rev. Bra. Plantas Med. 2010;12(4):406-413.

10. Matos FJA. Introducão à Fitoquímica Experimental. 2 ed. Fortaleza: UFC; 1997. 
Fabri, R. L. da Costa, J. A. B. M. Revista Eletrônica de Farmácia Vol. IX (2), 37 - 48, 2012.

11. Meyer BN, Ferrigni NR, Putnam JE, Jacobsen LB, Nichols DE, Maclaughlin JL. Brine shrimp: A convenient general bioassay for active plant constituents. Planta Med. $1982 ; 45(1): 31-34$.

12. Perez C, Pauli M, Bazerque P. An antibiotic assay by the well agar method. Acta Biol. Med. Exp. 1990;15:113-115.

13. Ahmad I, Mehmood, Mohammad F. Screening of some Indian medicinal plants for their antimicrobial properties. J. Ethnopharmacol.1998;62(2):183-193.

14. Reiser MJ, Gu ZM, Wood KV, Fang XP, Zeng L, McLaughlin JL. Five novel monotetrahydrofuran ring acetogenins from the seeds of Annona muricata. J. Nat. Prod. 1996;59(2):100-108.

15. MacLaughlin JL, Rogers LL. The use of biological assays to evaluate botanicals. Drug Inform. J. 1998;32(2):513-524.

16. Zani CL, Chaves PPG, Quiroz R, De Oliveira, AB, Cardoso JE, Anjos AMG, et al. Brine shrimp lethality assay as screening system for anti-Trypanosoma cruzi activity. Phytomedicine 1995;2(1):47-50.

17. Perez H, Días F, Medina JD. Chemical investigation and in vivo antimalarial activity of Tabebuia achraceae ssp. neochrysantha. Int. J. Pharmacogn. 1998;35(4):227-231.

18. Jones RN. Resistance patterns among nosocomial pathogens: trends over the past few years. Chest. 2001;119 Suppl 2:S397-404.

19. Prates MV, Bloch Júnior C. Peptídeos antimicrobianos. Biotecnology 2001;23:30-36.

20. Arruda EAG. Infecção hospitalar por Pseudomonas aeruginosa multi-resistente: análise epidemiológica HC-FMUSP. Rev. Soc. Bra. Med. Trop. 1998;31(5):503-504

21. Phillipson JD, O'Neil MJ. New leads to the treatment of protozoal infections based on natural product molecules. Acta Pharm. Nord. 1989;1:131-144.

22. Mendonza L, Wilkens M, Urzua A. Antimicrobial study of the resinous exudates and of diterpenoids and flavonoids isolated from some Chilean Pseudognaphalium (Asteraceae). J. Ethnopharmacol. 1997;58(2):85-88. 
Fabri, R. L. da Costa, J. A. B. M. Revista Eletrônica de Farmácia Vol. IX (2), 37 - 48, 2012.

23. Bagamboula CF, Uyttendaele $\mathrm{M}$, Debevere J. Antimicrobial and antioxidative activities of the essencial oils and methanol extracts of Salvia cryptanha (Montbret et Aucher ex Benth.) and Salvia multicaulis (Vahl.). Food Chem. 2004;84(4):519-525.

24. Geissman CS. Flavonoid compounds, tannins, lignins and related compounds. In: Florkin M, Stotz EH, editors. Pyrrole pigments, isoprenoid compounds and phenolic plant constituents. New York: Elsevier; 1963. 265p.

25. Scalbert A. Antimicrobial properties of tannins. Phytochemistry $1991 ; 30(12): 3875-$ 3883.

26. Mason TL, Wasserman BP. Inactivation of red beet beta glucan synthase by native and oxidized phenolic compounds. Phtyochemistry 1987;26(8):2197-2202.

27. Cushnie TPT, Lamb AJ. Antimicrobial activity of flavonoids. Int. J. Antimicrob. Ag. $2005 ; 26(5): 343-356$.

28. Ya C, Gaffney TH, Haslam E. Carbohydrate-polyphenol complexation. In: Hemingway RM, Karchesy JJ, editors. Chemistry and Significance of Condensed Tannins. New York: Plenum Press; 1988. 553p. 